University of Wollongong

Research Online

Faculty of Engineering and Information

Faculty of Engineering and Information

Sciences - Papers: Part A

Sciences

$1-1-2013$

Power quality emission assessment of photovoltaic inverters based on IEC technical report 61000-3-15:2011

Devinda Perera

University of Wollongong, bmdp065@uowmail.edu.au

Philip Ciufo

University of Wollongong, ciufo@uow.edu.au

Lasantha G. Meegahapola

University of Wollongong, lasantha.meegahapola@rmit.edu.au

Sarath Perera

University of Wollongong, sarath@uow.edu.au

Follow this and additional works at: https://ro.uow.edu.au/eispapers

Part of the Engineering Commons, and the Science and Technology Studies Commons

Research Online is the open access institutional repository for the University of Wollongong. For further information contact the UOW Library: research-pubs@uow.edu.au 


\title{
Power quality emission assessment of photovoltaic inverters based on IEC technical report 61000-3-15:2011
}

\author{
Abstract \\ The International Electrotechnical Committee Technical Report IEC 61000-3-15:2011 provides \\ electromagnetic compatibility requirements and test conditions for distributed generators up to $75 \mathrm{~A}$ per \\ phase. In the current research, two commercially available photovoltaic (PV) inverters up to the capacity \\ of $3600 \mathrm{~W}$ were tested following the guidelines proposed in IEC 61000-3-15 in relation to low order \\ harmonic emission and flicker emission. In addition, the harmonic and flicker emission behaviour of the \\ PV inverters were investigated under varying irradiation conditions. Both PV inverters were observed to \\ comply with the emission requirements prescribed by the technical report under most conditions except \\ for even order harmonics, which were observed to be in excess of the stipulated limits. Furthermore, \\ fluctuation in solar irradiation was observed not to have any significant impact on flicker emission of the \\ PV inverters under consideration.

\section{Keywords} \\ 61000, report, technica, iec, inverters, 3, photovoltaic, 15, assessment, emission, quality, power, 2011

\section{Disciplines} \\ Engineering | Science and Technology Studies

\section{Publication Details} \\ D. Perera, P. Ciufo, L. G. Meegahapola \& S. Perera, "Power quality emission assessment of photovoltaic \\ inverters based on IEC technica report 61000-3-15:2011," in Australasian Universities Power Engineering \\ Conference (AUPEC 2013), 2013, pp. 1-6.
}




\title{
Power Quality Emission Assessment of Photovoltaic Inverters based on IEC Technical Report 61000-3-15:2011
}

\author{
Devinda Perera*, Student Member, IEEE, Phil Ciufo, Senior Member, IEEE, \\ Lasantha Meegahapola, Member, IEEE and Sarath Perera, Senior Member, IEEE \\ Australian Power Quality and Reliability Centre, \\ School of Electrical, Computer and Telecommunications Engineering, \\ University of Wollongong, Australia. \\ bmdp065@uowmail.edu.au*
}

\begin{abstract}
The International Electrotechnical Committee Technical Report IEC 61000-3-15:2011 provides electromagnetic compatibility requirements and test conditions for distributed generators up to $75 \mathrm{~A}$ per phase. In the current research. two commercially available photovoltaic (PV) inverters up to the capacity of $3600 \mathrm{~W}$ were tested following the guidelines proposed in IEC 61000-3-15 in relation to low order harmonic emission and flicker emission. In addition, the harmonic and flicker emission behaviour of the PV inverters were investigated under varying irradiation conditions. Both PV inverters were observed to comply with the emission requirements prescribed by the technical report under most conditions except for even order harmonics, which were observed to be in excess of the stipulated limits. Furthermore, fluctuation in solar irradiation was observed not to have any significant impact on flicker emission of the PV inverters under consideration.
\end{abstract}

Index Terms-distributed generators, flicker, harmonics, photovoltaic inverters, power quality

\section{INTRODUCTION}

$\mathbf{T}$ HE proliferation of distributed generation (DG) such as photovoltaic (PV) generation systems in the LV distribution network can impact the power quality (PQ) in electrical networks [1]. The recently published IEC Technical Report IEC 61000-3-15 [2] focuses on proposing PQ emission limits for individual DG units up to $75 \mathrm{~A}$ per phase and providing guidelines on the assessments of PQ emission of such DG units under controlled conditions, in order to ascertain that DG units maintain adequate voltage quality in the distribution network in which they are connected. The power quality concerns addressed in [2] include low order harmonic emission, flicker and voltage fluctuations, DC injection, short and long duration over voltages and switching frequency harmonic emission. In the case of harmonics and flicker emission, the proposed emission limits and test procedures are mainly based on the corresponding equipment standards [3]-[6].

PV systems can inject low order harmonic current into the distribution grid as a consequence of the control strategy used, the background distortion present at the point of connection (PCC) and other well documented reasons [7], [8]. The impact of harmonic currents produced by PV systems on the harmonic voltage distortion of the distribution network mainly depends on the impedance of the supply grid. Hence, PV systems connected to weak distribution networks (i.e. characterised by a low short-circuit current ratio or high network supply impedance) can introduce excessive harmonic distortion to the network [2]. In addition, distribution networks may suffer from an increase in the levels of voltage fluctuations leading to flicker due to the output power fluctuations of the PV system induced by varying solar irradiation, especially in weak distribution networks. In spite of various field measurements and simulation work carried out in relation to harmonic and flicker emission from PV systems in established technical literature [9], [10], only limited research outcomes are available in the public domain [11] in which controlled experiments are carried out in a laboratory environment to investigate their PQ behaviour. Hence, the objective of the current research is to evaluate the PQ behaviour of PV systems in relation to harmonic and flicker emission by conducting PQ emission tests on two PVIs in a laboratory, following the procedures detailed in the IEC Technical Report [2]. The outcomes are then compared with the stipulated emission limits in [2].

The paper is organised as follows. Section II describes the laboratory experimental setup used for evaluation of PQ emission in PV systems. Section III summaries the outcomes when PVIs were tested under simulated public supply and under distorted supply conditions. Voltage fluctuations and flicker emission from the PVIs under normal operation are investigated in Section IV. The PQ behaviour of the PVIs, when the PV arrays connected to the PVIs are subjected to fluctuations of irradiance and ambient temperature is analysed in Section V. Conclusions are given in Section V.

\section{EXPERIMENTAL SETUP}

The IEC technical report categorises all DGs into two main types as; DGs with rated current less than $16 \mathrm{~A}$ and DGs with rated current above $16 \mathrm{~A}$ and less than $75 \mathrm{~A}$. The test setup and test conditions can vary based on the rated current of the DG. The general schematic of the test setup used to evaluate the PQ emission from the PV systems (i.e. PV inverters) is given in Fig. 1. The details of the differences between test setup and test conditions are addressed in subsequent sections.

The key components of the test setup are explained as follows:

- AC power source - California Instrument MX30 programmable AC power source was used to emulate the public supply. The source is capable of absorbing active and reactive power supplied by the PVI and simulating various pre-distortion levels required for test conditions specified in [2]. 


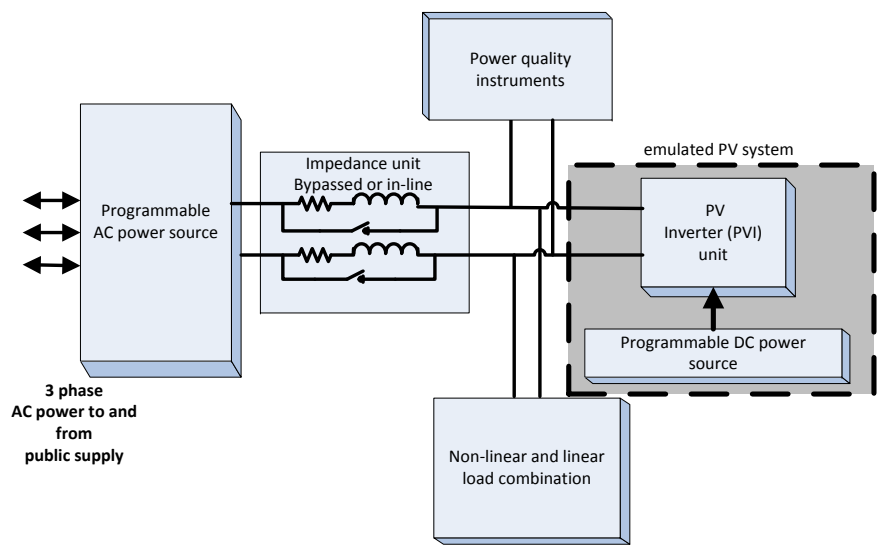

Fig. 1. Experimental setup for PQ emission tests

- Programmable DC source - The purpose of the DC source is to emulate the PV array which feeds power to the PVI under testing. AMATEK TerraSAS PV simulator ETS 1000/10 was used as the DC power source in the experimental setup. The PV emulator is capable of simulating the variation of power output of a PV array under varying irradiance and ambient temperature.

- Impedance unit ${ }^{1}$ - The impedance network consisting of phase impedance of $0.15+\mathrm{j} 0.15 \Omega$ and neutral impedance of $0.10+\mathrm{j} 0.10 \Omega$ which can be in-line or by-passed was used in the test setup. When used in-line any non-linear current flowing to and from the PVI or load will cause voltage distortion on the inverter side of impedance

- Linear and non-linear loads - Chroma programmable ac/dc electronic loads (model number 63804) were used to simulate linear and non-linear loads found in homes and offices.

- A Hioki PW3198 PQ analyser was used to record power quality data including the harmonic currents, harmonic voltages and flicker levels. In addition, Agilent Technologies DS07034A four channel oscilloscope was used to capture current and voltage waveforms.

- Two commercial single-phase PVI units of which the details are given below were tested.

- Inverter one - $3600 \mathrm{~W}$ transformer-less PVI operating at unity power factor, with nominal input DC voltage of $360 \mathrm{~V}$ and maximum input current of $10 \mathrm{~A}$ per array. A maximum of two arrays can be connected to the $\mathrm{PVI}^{2}$.

- Inverter two - $2100 \mathrm{~W}$ transformer based PVI operating at unity power factor, with nominal input DC voltage of $200 \mathrm{~V}$ and maximum input current of $20 \mathrm{~A}$.

${ }^{1}$ For all DGs with rated current below $16 \mathrm{~A}$ the test impedance proposed in [2] correspond to the IEC 60725 reference impedance, which is $0.4+\mathrm{j} 0.25 \Omega$ consisting of phase impedance of $0.24+\mathrm{j} 0.15 \Omega$ and neutral impedance of $0.16+\mathrm{j} 0.10 \Omega$; whereas, for all DGs with rated current below $75 \mathrm{~A}$ (and above $16 \mathrm{~A})$ the test impedance is $0.25+\mathrm{j} 0.25 \Omega$ consisting of phase impedance of $0.15+\mathrm{j} 0.15 \Omega$ and neutral impedance of $0.1+\mathrm{j} 0.1 \Omega$. However, due to the unavailability of the IEC 60725 reference impedance all test cases were conducted using the test impedance of $0.25+0.25 \mathrm{j} \Omega$.

${ }^{2}$ According the manufactures' data the PVI complies with limits established by IEC 61000-3-11 and IEC 61000-3-12. Hence, the PVI was considered to belong to the category of DGs with rated current above $16 \mathrm{~A}$ and below $75 \mathrm{~A}$

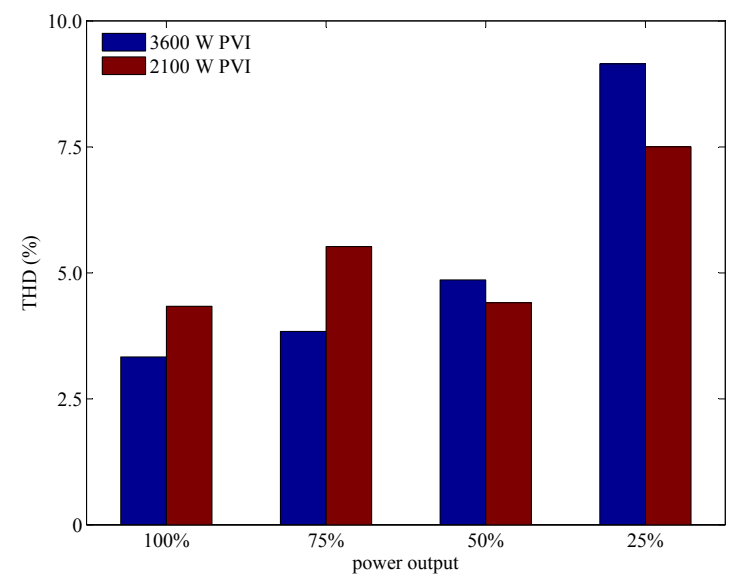

Fig. 2. THD of current of each PVI for power outputs of $100 \%, 75 \%, 50 \%$ and $25 \%$ of their nominal power respectively

\section{AsSESSMENT OF HARMONIC CURRENT EMISSION FROM A PVI}

In order to verify that PV systems do not significantly exacerbate either current or voltage distortion levels in a distribution network, the Technical Report IEC 61000-3-15 [2] proposes two different tests to be carried out on the PVI. In the first test, named the "product test", PVIs are tested for harmonic current emission under simulated public supply network conditions [2]. The product test method utilises the test set up given in Fig. 1 with the impedance unit bypassed. If the PVI meets the stipulated emission limits in [2], the PV system is expected to function properly in all but the most exceptional cases.

In addition, the network in which the PV system is connected may not be ideal and have pre-existing distortion voltage levels; hence, the additional voltage distortion caused by the operation of PVI is required to be limited. In addition, the effects that high crest factor loads ${ }^{3}$ such as TVs, computers and microwaves have on PVIs should be known. Therefore, a supplementary test named the "system test" is proposed in [2] in which the increase in voltage total harmonic distortion (THD) due to the connection of a PVI is compared against a prescribed value. The system test method utilises the same experimental setup as in the product test with the impedance unit connected in-line with the test setup. In addition, linear and non-linear loads are used to generate the specified preexisting distortion levels which emulate the actual conditions of the public supply network.

In the following section, the aforementioned tests were conducted on the two PVIs introduced in Section II and the corresponding the results are presented.

\section{A. Harmonic Emission of PVIs Connected to a Simulated Pubic Supply - The Product Test}

Each PVI was connected to the test setup as shown in Fig. 1 with the AC source voltage set to a nominal voltage of $230 \mathrm{~V}$. Based on the PVI rated current, the corresponding predistortion levels as given by clause 7.2.4 of [2] were introduced to the $\mathrm{AC}$ source voltage, in-order to emulate the public power

\footnotetext{
${ }^{3}$ Crest factor is defined as the ratio of peak value to the root-mean-square (rms) value of the current waveform
} 

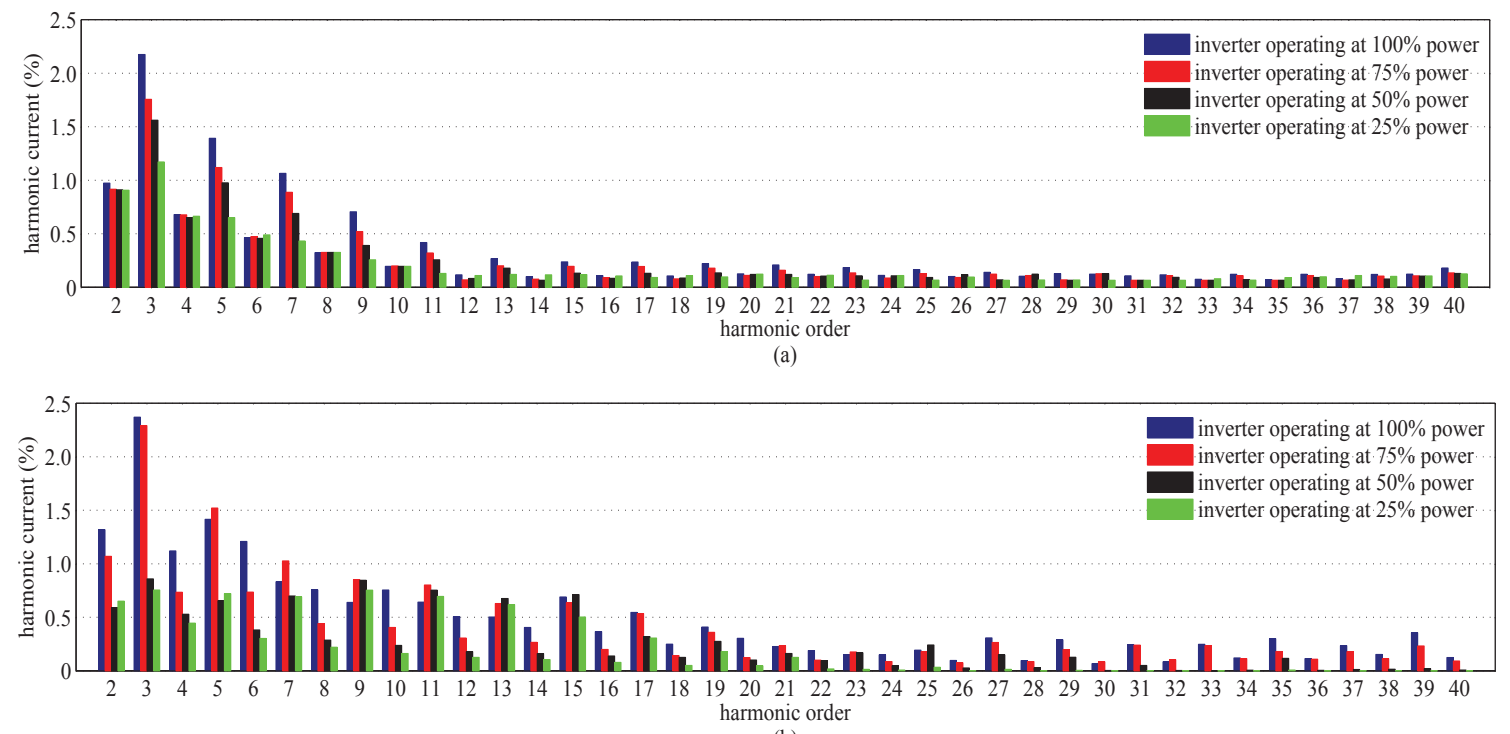

(b)

Fig. 3. Harmonic current emission levels for various output power levels; (a) $3600 \mathrm{~W}$ PVI (b) $2100 \mathrm{~W}$ PVI

TABLE I

HARMONIC CURRENT EMISSION LIMITS FOR DGS UP TO 75 A/PHASE (IN PERCENT OF $\mathrm{I}_{\text {rms }}$ )

\begin{tabular}{|c|c|c|c|c|c|c|c|c|c|}
\hline harmonic order & 2 & 3 & 5 & 7 & 9 & 11 & 13 & $\begin{array}{c}15-39 \\
\text { odd harmonics }\end{array}$ & $\begin{array}{c}4-40 \\
\text { even harmonics }\end{array}$ \\
\hline For DG $>600 \mathrm{~W}$ & $1.0 \%$ & $21.6 \%$ & $10.7 \%$ & $7.2 \%$ & $3.8 \%$ & $3.1 \%$ & $2.0 \%$ & \multicolumn{1}{|c|}{$1.0 \%$} & $1.0 \%$ \\
\hline
\end{tabular}

supply. As some PVIs with DC/AC current control will use open loop control for low power levels and closed loop control for high power levels [2] (which in turn affects their harmonic behaviour), each PVI was tested at $100 \%, 75 \%, 50 \%$ and $25 \%$ of their rated power by adjusting the irradiance and temperature inputs to the PV simulator (hence, the available output power of the PV simulator). Harmonic current emission of each PVI was recorded using the power quality analyser following the procedures specified in [3]. Fig. 2 illustrates THD of the current ${ }^{4}$ of each PVI for various power levels.

According to Fig. 2 the current THD of each PVI increases when they are operated at a lower power level than the nominal power. In the case of the $3600 \mathrm{~W}$ PVI, the THD increases from $3.33 \%$ to $9.15 \%$ when the power output of the PVI is reduced from $100 \%$ to $25 \%$ of its nominal power output respectively. However, for the $2100 \mathrm{~W}$ PVI, the THD has slightly reduced when the power output is reduced from $75 \%$ to $50 \%$ but increased to $8.23 \%$ for $25 \%$ power output.

The harmonic current emission levels of both PVIs are given in Fig. 3. The levels given are derived as a percentage of the average rms current of the PVI when each PVI is operating at $100 \%$ nominal power. Table I provides the proposed harmonic current emission limits for DGs with a VA capacity of greater than $600 \mathrm{~W}$ as given in [2]. With reference to Fig. 3, although the current THD of each PVI increases when the output power decreases, the harmonic current emission level (in amperes) can be observed to decrease for most cases. In addition the harmonic current emission of each PVI can be observed to comply with the odd harmonic current emission limits specified in Table I. However, for the $2100 \mathrm{~W}$ PVI the $2^{\text {nd }}$, $4^{\text {th }}$ and $6^{\text {th }}$ harmonics are in excess of limits stipulated in

${ }^{4}$ Current THD is defined as a percentage of fundamental current
Table. I.

Fig. 4 illustrates the harmonic phase angle variations of $3^{\text {rd }}$, $5^{\text {th }}, 7^{\text {th }}$ and $9^{\text {th }}$ order harmonics for different output power levels of the $3600 \mathrm{~W}$ PVI. The corresponding harmonic phase angle diversity of each harmonic order is observed to be less and is clustered around a particular phase angle irrespective of the variation of output power. Similar observations were made with respective to the higher order odd harmonics and even harmonics.

\section{B. Harmonic Emission of a PVI under Distorted Grid Condi- tions - The System Test}

The system test utilises the same test setup discussed in Section II with the addition of an impedance network and additional linear and non-linear loads. Six test cases, as given by Table II, were conducted on two PVIs. Cases two to six are part of the system test specified by the [2]. In the first case, a linear load with an active power capacity equal to that of the PVI nominal power was connected to the AC source through the test impedance and the AC source was programmed to produce a pure sinusoidal waveform. The voltage THD at the load side of the test impedance was measured. Thereafter, the PVI operating at its rated power was connected to the load side of the test impedance and the increase in the voltage THD was recorded. Similar steps were followed for cases two and three, however, the AC source was programmed to produce a flat top waveform and peaky waveform (as specified by clause 7.5 .2 [2]) with voltage THD of $4 \%$ respectively. For cases four to six, the AC source was programmed to produce a pure sinusoidal waveform, however, the voltage THD at the load side of the test impedance was set using linear and non-linear load combinations with active power 

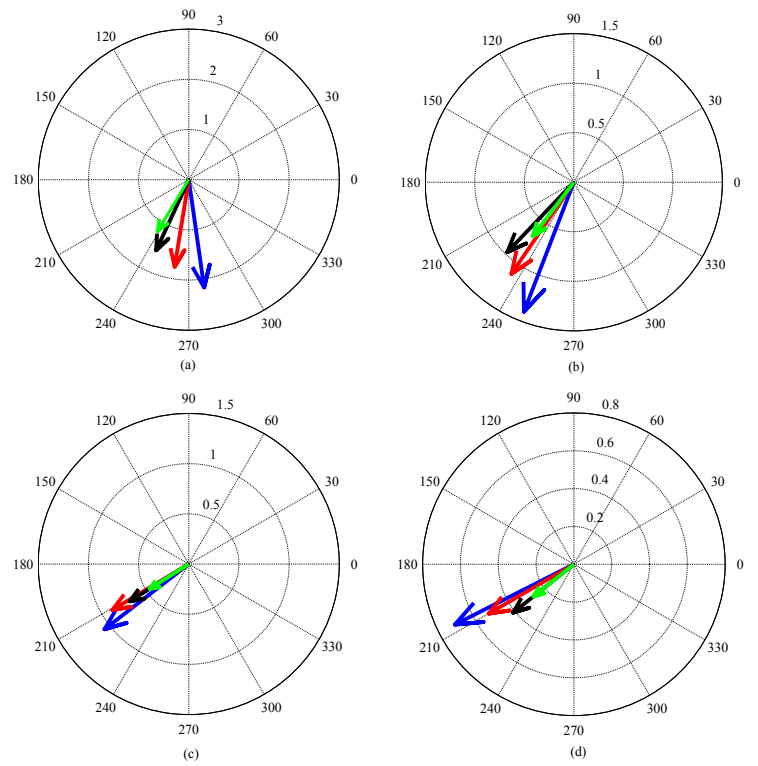

Fig. 4. Phase angle diversity of (a) $3^{\text {rd }}$ (b) $5^{\text {th }}$ (c) $7^{\text {th }}$ (d) $9^{\text {th }}$ harmonic currents in $3600 \mathrm{~W}$ PVI for power outputs of $100 \%, 75 \%, 50 \%$ and $25 \%$ of its nominal power (blue $-100 \%$ rated power, red $-75 \%$ rated power, black $50 \%$ rated power, green $-25 \%$ rated power

capacities as given by Table II. This combination replicates high crest factor loads commonly found in LV distribution networks [12]. The increment of the voltage THD at the load side of the impedance and the THD of the current of the PVI for all six cases for each PVI are given in Fig 5-(a) and 5-(b) respectively.

If the voltage THD before the connection of the PVI is less than $5 \%$ and the increment of the voltage THD after the connection of the PVI is less than $1 \%$ absolute, the PVI is deemed to pass the system test (provided that they pass the product test) and is expected to function satisfactorily when connected to the actual distribution network [2]. According to the test results given in Fig. 5, the increment of the voltage THD is less than $1 \%$ for most cases, except for case five for the $3600 \mathrm{~W}$ PVI where the increment of the voltage THD is $1.2 \%$. The post-connection voltage THD can be observed to be less than the pre-connection voltage THD value for case three using the $2100 \mathrm{~W} \mathrm{PVI}^{5}$. Referring to Fig. 5, the current THD of the PVIs for cases one to three show only a marginal variation. However, when the $3600 \mathrm{~W}$ PVI is connected together with a high crest factor load (replicated by the non-linear load) the current THD has increased. The opposite behaviour is observed in the case of the 2100 W PVI.

\section{VOLTAGE FluCtUATIONS AND FLICKER UNDER NORMAL OPERATION}

In this section both PVIs were tested for their flicker emission using the test conditions specified by [2] and [5]. The experimental setup given in Section II was used, with the test impedance of $0.25+\mathrm{j} 0.25 \Omega$ connected between the AC source and the PVI. The source voltage was maintained at the

${ }^{5}$ Note that the direct comparison of the increase in voltage THD should not be made with the prescribed value in [2] in the case of $2100 \mathrm{~W}$ PVI, as the proposed test impedance value in [2] is different to the test impedance used in the experiment
TABLE II

TEST CASES

\begin{tabular}{|c|c|c|c|}
\hline Case & Load & DG Supply & Pre-distortion Limit \\
\hline 1 & $100 \%$ linear load & $100 \%$ & pure sine wave \\
\hline 2 & $100 \%$ linear load & $100 \%$ & $4 \pm 0.2 \%$ set by the source \\
\hline 3 & $100 \%$ linear load & $100 \%$ & $4 \pm 0.2 \%$ set by the source \\
\hline 4 & $\begin{array}{c}50 \% \text { linear load } \\
50 \% \text { non-linear load }\end{array}$ & $100 \%$ & $\begin{array}{c}4 \pm 0.2 \% \text { set by the } \\
\text { the loads }\end{array}$ \\
\hline 5 & $\begin{array}{c}25 \% \text { linear load } \\
25 \% \text { non-linear load }\end{array}$ & $100 \%$ & $\begin{array}{c}2.5 \pm 0.2 \% \text { set by the } \\
\text { the loads }\end{array}$ \\
\hline 6 & $\begin{array}{c}25 \% \text { linear load } \\
25 \% \text { non-linear load }\end{array}$ & $50 \%$ & $\begin{array}{c} \pm 0.2 \% \text { set by the } \\
\text { the loads }\end{array}$ \\
\hline
\end{tabular}
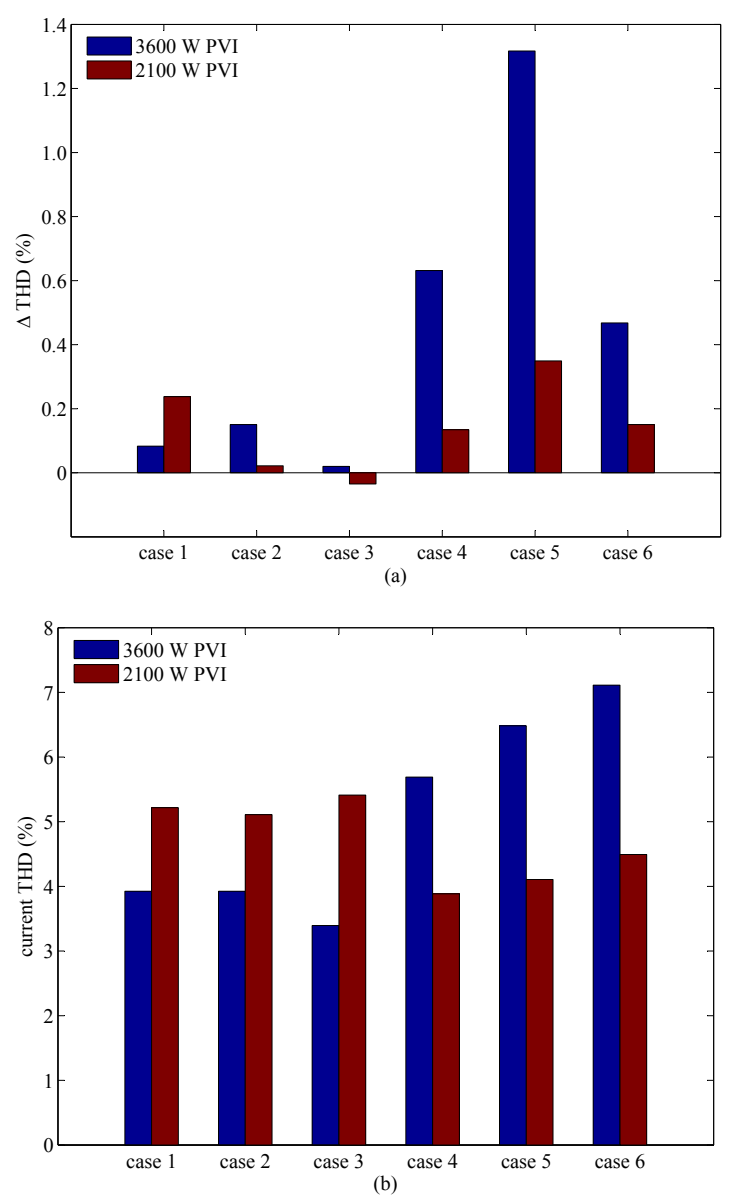

Fig. 5. (a) Increase in the voltage THD for cases 1-6 (b) Current THD of the PVI for cases 1-6

nominal voltage of $230 \mathrm{~V}$, a frequency of $50 \mathrm{~Hz}$, the THD of the supply voltage at $0.18 \%$ and the flicker reading of 0.039 of the source voltage in-order to meet the requirements specified by [5].

A 10 min. test was performed for each PVI operating at $100 \%, 75 \%, 50 \%$ and $25 \%$ of their respective nominal power output and flicker emission at the inverter side of the impedance was recorded using an IEC flickermeter. Fig. 6 illustrates the half cycle relative voltage change characteristics at the inverter side of the test impedance for a period of $0.2 \mathrm{~s}$, when both PVIs are operating at the $100 \%$ power output. Note that the observation were made during the normal operation of the PVIs (i.e. while the PVIs remain connected to the test network). Referring to the Fig. 6, the 3600 W PVI exhibits relative voltage changes slightly greater than that of the 2100 W PVI. During normal operation of the PVI, the irradiance and temperature inputs to the PV simulator were 

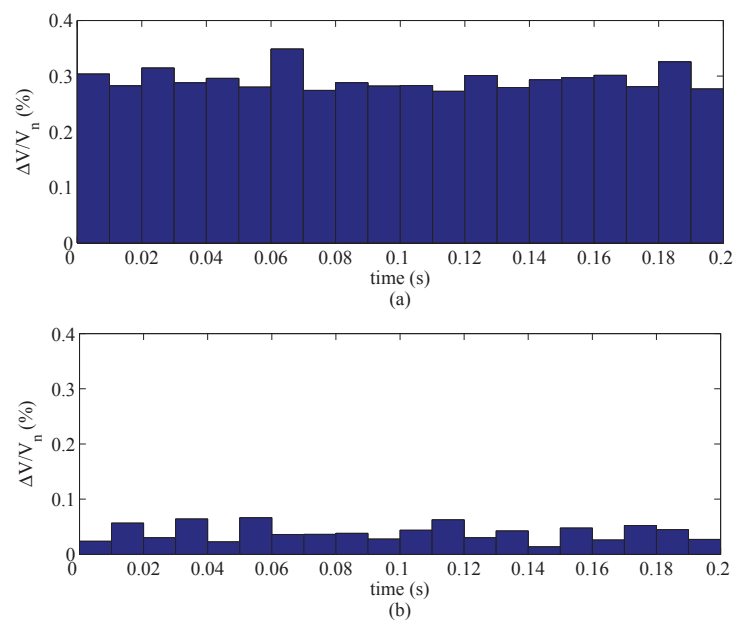

Fig. 6. Relative voltage change characteristics at the inverter side of the impendence for (a) $3600 \mathrm{~W}$ PVI, (b) $2100 \mathrm{~W}$ PVI

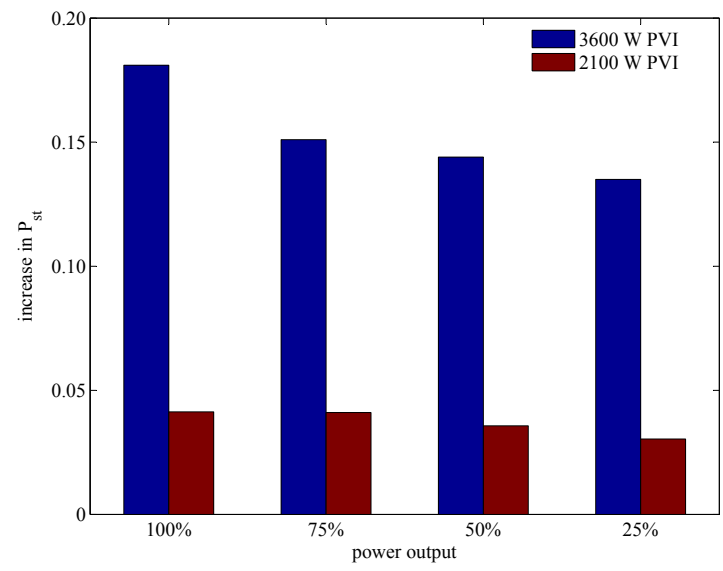

Fig. 7. Flicker emission from PVIs when operating at $100 \%, 75 \%, 50 \%$ and $25 \%$ of their nominal power

maintained at a constant value; hence, the output power of the simulated PV array was held at a constant value. Therefore, a possible reason for voltage fluctuations experienced could be the PVI control functions including the maximum power point tracking operation.

Fig. 7 illustrated the increase in the flicker emission of each PVI for output power levels of $100 \%, 75 \%, 50 \%$ and $25 \%$ respectively. The results presented in Fig. 7 have been rescaled for the reference impedance value in the case of $2100 \mathrm{~W}$ PVI as specified by [6]. The flicker emission from the $3600 \mathrm{~W}$ PVI is greater compared to the 2100 W PVI. Furthermore, the flicker emission can be observed to reduce with the output power of each PVI. According to the limits stipulated by [2], if the increase in the flicker measurements are less than 0.5, PVIs are expected to function satisfactorily when connected to the actual distribution network. Accordingly, the flicker emission from each PVI given Fig. 7, can be observed to be significantly small, compared to the limits established by [2].

\section{Power Quality Assessment of PVIS UNDER VARYING IRRADIANCE AND TEMPERATURE}

PV arrays are subjected range of conditions including

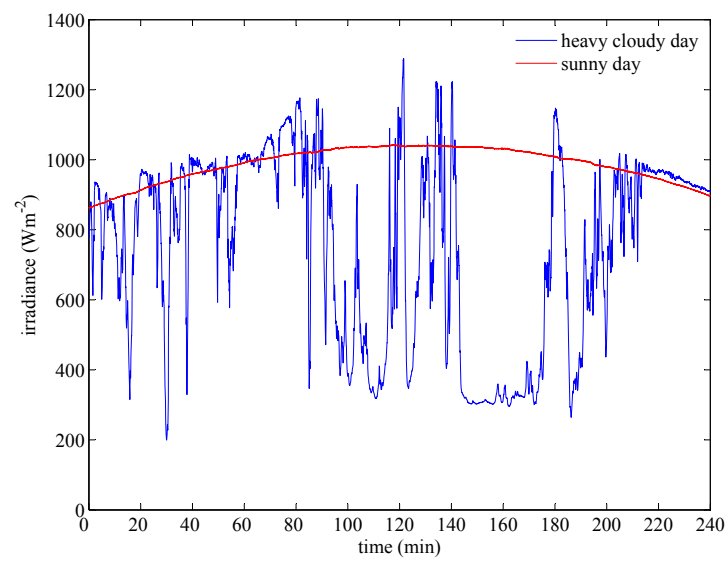

Fig. 8. Fluctuation of incident irradiance of a PV array during a heavy cloudy day and a sunny day during a four hour window
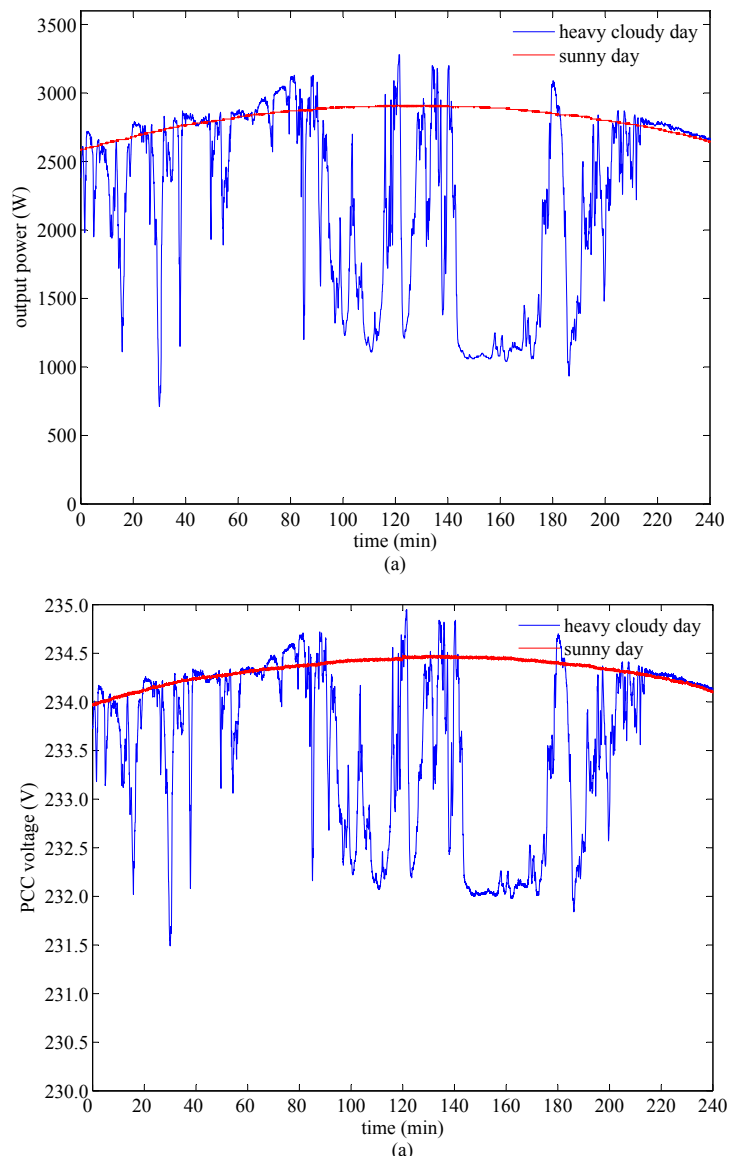

Fig. 9. (a) Power fluctuations of the $3600 \mathrm{~W}$ PVI during a heavy cloudy day and a sunny day, (b) Voltage fluctuations at the inverter side of the impedance of the $3600 \mathrm{~W}$ PVI during a heavy cloudy day and a sunny day

dynamic irradiance and ambient temperature during their operation, which could affect the PQ performance of the PVIs to which they are connected. In this section the PQ performance of the two PVIs introduced in Section II were analysed when the PV arrays connected to the PVI are subjected to fluctuating irradiance levels and ambient temperature, using the test setup used in Section II. Two cases were considered. In the first case, the PV simulator was programmed to emulate the output of a PV array when subjected to a fluctuating irradiance pattern 


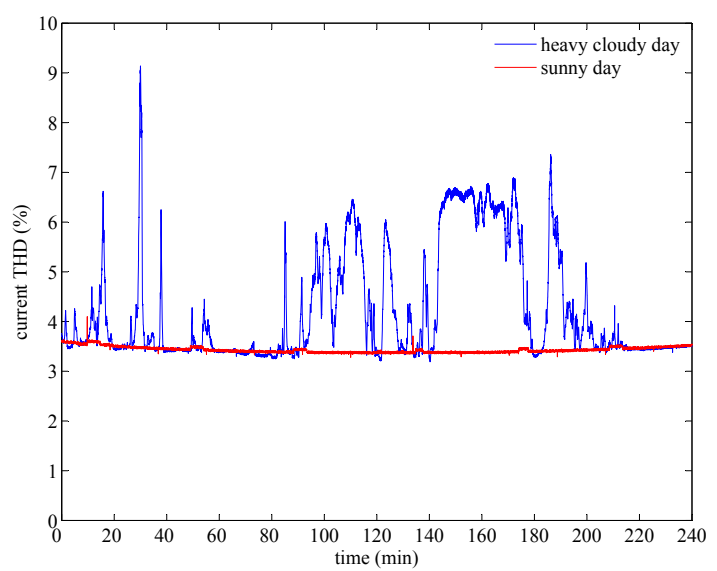

Fig. 10. Variation of the current THD of the 3600 W PVI during a heavy cloudy day and a sunny day

associated with a four hour time window of a heavy cloudy day as given in Fig. 8. In the second case, the irradiance pattern associated with a sunny day as given by Fig. 8 was considered. The fluctuation on ambient temperate is also appropriately considered in each test case. For brevity, only the outcomes associated with the $3600 \mathrm{~W}$ PVI are presented. The associated active power output of the PVI, the voltage at the inverter side of the impedance unit, the THD of the PVI current, for the four hour time window corresponding to heavy cloudy day and sunny day are given in Fig. 9-(a), Fig. 9-(b) and Fig. 10 respectively.

According to Fig. 8 and Fig. 9, the output power of the PVI can be seen to be co-related to the incident irradiation on the PV array for both test cases. An approximate linear relationship between the power output and irradiance was observed, which is slightly affected by the ambient temperature. The voltage fluctuations at the inverter side of the test impedance are observed to follow the variation of the PVI output power. As presented in Section III-A, the current THD of the PVI was observed to increase under low irradiance conditions.

Fig. 11 illustrates the flicker emission of the $3600 \mathrm{~W}$ and $2100 \mathrm{~W}$ PVIs for a four hour time window during a heavy cloudy day and a sunny day. The flicker emission levels are observed to be relatively insignificant. Flicker levels for both cloudy and sunny day can be observed to be higher in the case of $36000 \mathrm{~W}$ PVI, compared to that of the $2100 \mathrm{~W}$ PVI. For the $3600 \mathrm{~W}$ PVI, the flicker emission during the cloudy day and sunny day shows only a negligible difference, whereas for the $2100 \mathrm{~W}$ PVI, the flicker emission during the cloudy day is higher than the flicker emission from the same PVI during a sunny day. Accordingly, the influence of the internal controls on flicker emission are predominant in the case of the $3600 \mathrm{~W}$, whereas the flicker emission from the $2100 \mathrm{~W}$ PVI is more susceptible to the changes in the incident irradiation on the PV array.

\section{CONCLUSION}

This paper reports on the results of an experimental study carried out on two, commercial PVIs in order to evaluate the harmonic and flicker emission. A series of tests, as specified by IEC Technical Report IEC 61000-3-15 were performed using the PVIs, and the results were compared against the stipulated limits. Both PVIs complied with the prescribed limits for har-

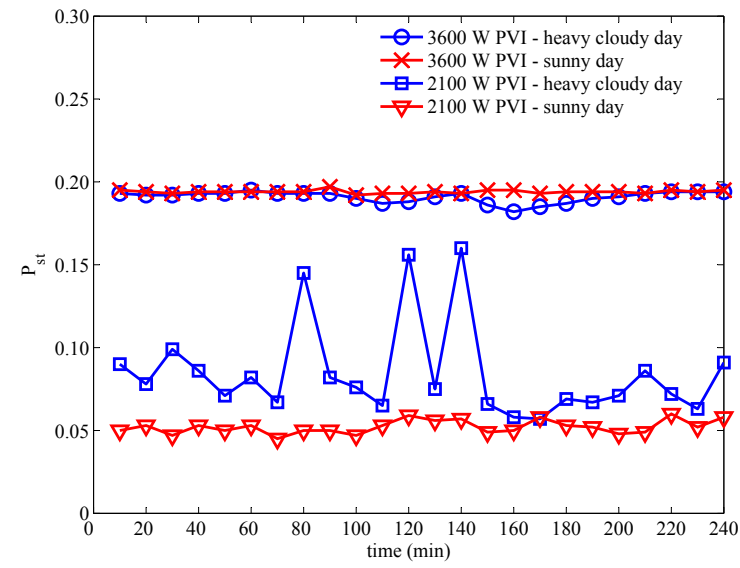

Fig. 11. Flicker emission of the $3600 \mathrm{~W}$ and $2100 \mathrm{~W}$ PVI during a heavy cloudy day and a sunny day

monics and flicker emission, except for even harmonics, where excessive $2^{\text {nd }}, 4^{\text {th }}$ and $6^{\text {th }}$ order harmonics were observed in the case of the lesser rated PVI. In addition, harmonic and flicker emission from the PVIs was measured when the PV arrays were subjected to fluctuations in irradiance and ambient temperature associated with a heavy cloudy day and a sunny day. Recorded flicker emission levels were insignificant, which implies that voltage variations caused by the passing clouds do not substantially affect the flicker emission from the PVI in the studied case.

\section{REFERENCES}

[1] M. Bollen and F.Hassan, "Integration of Distributed Generation in the Power System,” First Ed., IEEE Press, 2011.

[2] "Electromagnetic compatibility (EMC) - Part 3-15: Limits - Assessment of low frequency electromagnetic immunity and emission requirements for dispersed generation systems in LV network," IEC Technical Report 61000-3-15, Ed. 1.0, International Electrotechnical Commission, 2011.

[3] "Electromagnetic compatibility (EMC) - Parts 3-2: Limits - Limits for harmonic current emissions (equipment input current (16 A per phase)," IEC 61000-3-2, Ed. 3.0, International Electrotechnical Commission, 2005.

[4] "Electromagnetic compatibility (EMC) - Parts 3-12: Limits - Limits for harmonic currents produced by equipment connected to public lowvoltage systems with input current $\geq 16$ A and $\leq 75$ A per phases," IEC 61000-3-12, Ed 1.0, International Electrotechnical Commission, 2004.

[5] "Electromagnetic compatibility (EMC) - Parts 3-3: Limits - Limitation of voltage changes, voltage fluctuations and flicker in public low-voltage supply systems, for equipment with rated current $\leq 16$ A per phase and not subject to conditional connection," IEC 61000-3-3, Ed. 1.2, International Electrotechnical Commission, 2005

[6] "Electromagnetic compatibility (EMC) - Parts 3-11: Limits - Limitation of voltage changes, voltage fluctuations and flicker in public low-voltage supply systems Equipment with rated current less than or equal to 75 A and subject to conditional connection," IEC 61000-3-11, Ed. 1.2, International Electrotechnical Commission, 2000.

[7] M. Armstrong, D.J. Atkinson, C.M. Johnson and T.D. Abeyasekera "Low order harmonic cancellation in a grid connected multiple inverter system via current control parameter randomization," IEEE Trans. on Power Electronics, vol.20, no.4, pp.885-892, July 2015.

[8] A. Kulkarni and V. John, "Mitigation of Lower Order Harmonics in a Grid-Connected Single-Phase PV Inverter," IEEE Trans. on Power Electronics, vol.28, no.11, pp.5024-5036, Nov. 2013.

[9] J.H.R. Enslin and et al. "Harmonic interaction between large numbers of photovoltaic inverters and the distribution network," in Proc. IEEE Power Tech Conf., Bologna, vol.3, 23-26 June 2003.

[10] S.B. Kjaer, "Flicker and photovoltaic power plants," in Proc. 25th European Photovoltaic Solar Energy Conference and Exhibition Valencia, 6-10 Sept. 2010.

[11] M. van den Bergh, "Solar inverter testing per IEC 61000-3-15," in Proc. Int. conf. on Electricity Distribution, Frankfurt, June. 2011.

[12] AMETEK Inc, "Comprehensive Test Solutions for Domestic Grid-Tied Solar Inverters," 2010 